\title{
VARIATIONS IN BRANCHING PATTERN OF SEGMENTAL BRONCHI IN LUNGS USING CONVENTIONAL DISSECTION METHOD
}

\section{Umesh. S. ${ }^{1}$, Khizer Hussain Afroze. $M{ }^{* 2}$, Sangeeta. $M^{3}$.}

${ }^{1}$ Assistant professor, Department of Anatomy, MVJ Medical College \& Research Hospital, Hoskote, Bangalore. Karntaka. India.

${ }^{* 2}$ Assistant professor, Department of Anatomy, MVJ Medical College \& Research Hospital, Hoskote, Bangalore. Karntaka. India.

${ }^{3}$ Professor \& HOD, Department of Anatomy, MVJ Medical College \& Research Hospital, Hoskote, Bangalore. Karntaka. India.

\section{ABSTRACT}

Introduction: The anatomical knowledge of tracheobronchial tree and its variations will be useful in case of many interventional treatments. Hence we undertook the present study to document the variation in branching pattern of segmental bronchi and its clinical implication.

Materials and Methods: The Study was done on 30 right \& 30 left formalin fixed adult lungs obtained from the cadavers in the Department of Anatomy, Kempegowda Institute of Medical Sciences, Bangalore. The lung was dissected along the primary bronchi to expose the branching pattern, till the segmental bronchi. Ramification of bronchial tree was observed and photographed.

Results: Regular pattern of $B 1$ to $B 10$ was found to be more on right side (76.6\%), Absence of B7 was also more on right side. The pattern $B 7, B 8+9+10(6.6 \%)$, was seen only on right side, whereas the patterns, $B 1+B 2, B 3, B 7+8, B 9+10$, $B 7, B 8, B 9+10$ and $B 7+8, B 9, B 10$ was seen only in the left lungs. Two left lungs exhibited an accessory bronchus after lingual division and three left lungs had three bronchi in lingual division.

Conclusions: The knowledge of anatomical variability of branching pattern will be useful for interventional radiologist, which would help to diagnose or predict many adverse outcomes of chest diseases at earlier stage and surgeons for planning segmental resections or pulmonary lobectomy.

KEY WORDS: Bronchopulmonary segments, Bronchial disease, lobectomy, segmentectomy, resection of lung.

Address for Correspondence: Dr. Khizer Hussain Afroze. M, Assistant Professor, Department of Anatomy, MVJ Medical College \& Research Hospital, Hoskote, Bangalore. Karntaka. India. 562114. Mobile: +91-9901770170. E-Mail: drafroze.homoeo@gmail.com

Access this Article online Quick Response code

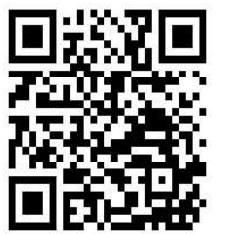

DOI: $10.16965 /$ ijar.2019.252

Journal Information

International Journal of Anatomy and Research

ICV for 2016
90.30
ISSN (E) 2321-4287 | ISSN (P) 2321-8967 https://www.ijmhr.org/ijar.htm DOI-Prefix: https://dx.doi.org/10.16965/ijar

\section{Article Information}

Received: 14 Jun 2019

Peer Review: 14 Jun 2019

Revised: None
Accepted: 05 Aug 2019

Published (O): 05 Sep 2019

Published (P): 05 Sep 2019

\section{INTRODUCTION}

The Trachea or the windpipe through which air enters the lung, is divided into principal bronchus (right and left) which further divides into lobar bronchi, three for right lung (superior, intermediate and inferior) and two for left lung (superior and inferior). Finally, each lung consists of ten bronchopulmonary segements [1]. The branching pattern of tracheobronchial tree of lungs have not received appropriate clinical attention although it serves a major role in respiration until the recent decades. Routine anatomical and morphological evaluations of lungs are restricted for assessment of fissures and lobes. In the extensive review of literature, 
we encountered many studies on tracheobronchial tree upto primary bronchi. There is enough information in previous studies about the normal branching pattern of primary bronchi [2-6]. But there is paucity in literatures regarding the branching pattern of segmental bronchi especially using conventional dissection method [7-9].

The preoperative knowledge of tracheobronchial anatomy and its variations will be useful in case of interventional treatments like intubation and other operative procedures like brachytherapy, postural drainage, bronchial thermoplasty, segmental lung resection and laser therapy. Hence we undertook the present study to document the variation in branching pattern of segmental bronchi and its clinical implication.

\section{MATERIALS AND METHODS}

The Study was done on 30 right \& 30 left formalin fixed adult lungs irrespective of their sex, obtained from the cadavers in the Department of Anatomy, Kempegowda Institute of Medical Sciences, Bangalore. Gross dissection of the thorax was done by following the guidelines of Cunningham's Manual of Practical Anatomy, fifteen editions. Anterior thoracic wall was cut with costotomy and elevated. The lungs were extracted out carefully. Mutilated specimens, with malformation and deformities were excluded.

The lung was dissected along the primary bronchi to expose the branching pattern, till the segmental bronchi. Ramification of bronchial tree was observed and photographed. The segmental bronchi according to lobes were labeled as follows.

\section{Right Upper Lobe (RUL) \& Right Middle Lobe}

(RML): RUL has three segmental bronchi such as apical, posterior and anterior which was labeled as B1, B2 and B3 respectively. RML has two segmental bronchi i.e. lateral and medial which were labeled as B4 and B5 respectively.

Left Upper Lobe (LUL): Five segmental bronchi was renowned in LUL designated as apical (B1), posterior (B2), anterior (B3), Superior lingular (B4) and Inferior lingular (B5).

Right Lower Lobe (RLL) \& Left Lower Lobe (LLL): The lower lobe segmental bronchi on both sides are similar and were labeled as follow, superior (B6), medial basal (B7), anterior basal (B8), lateral basal (B9) and Posterior basal (B10).

Accessory segmental bronchi: was represented as $\mathrm{Bx}$.

\section{RESULTS}

Table 1 and 2 shows the incidence of variation in the branching pattern of segmental bronchi. Regular pattern of B1 to B10 was found to be more on right side $(76.6 \%)$ whereas variations were found in 7 lungs which accounts for $23.4 \%$. Out of 7 lungs, the incidence of absence of $B 7$ and the pattern $B 7, B 8+9+10$ were observed in 5 lungs (16.7\%) and in 2 lungs (6.7\%) respectively (Figure 1\& 2).

Table 1: The incidence of patterns of segmental bronchi in left upper, right upper and right middle lobes.

\begin{tabular}{|c|c|c|c|c|}
\hline \multirow{2}{*}{$\begin{array}{c}\text { Pattern of Segmental } \\
\text { bronchi }\end{array}$} & \multicolumn{2}{|c|}{ Right Lungs } & \multicolumn{2}{c|}{ Left Lungs } \\
\cline { 2 - 5 } & No & $\%$ & No & $\%$ \\
\hline B1,B2,B3 & 30 & 100 & 28 & 93.3 \\
\hline B1+B2,B3 & -- & -- & 2 & 6.7 \\
\hline $\begin{array}{c}\text { B4, B5 superior \& inferior } \\
\text { lingular }\end{array}$ & -- & -- & 25 & 83.3 \\
\hline B4, B5 medial \&lateral & 30 & 100 & -- & -- \\
\hline $\begin{array}{c}\text { An extra bronchus after } \\
\text { lingular division }\end{array}$ & -- & -- & 2 & 6.7 \\
\hline $\begin{array}{c}\text { Three bronchi in the } \\
\text { lingular division }\end{array}$ & -- & -- & 3 & 10 \\
\hline
\end{tabular}

Table 2: The incidence of patterns of segmental bronchi in right lower and left lower lobes.

\begin{tabular}{|c|c|c|c|c|}
\hline $\begin{array}{c}\text { Pattern of Segmental } \\
\text { bronchi }\end{array}$ & \multicolumn{2}{|c|}{ Right Lungs } & \multicolumn{2}{c|}{ Left Lungs } \\
\cline { 2 - 5 } & No & $\%$ & No & $\%$ \\
\hline B6 & 30 & 100 & 30 & 100 \\
\hline B7 absent & 5 & 16.7 & -- & -- \\
\hline B7,B8, B9,B10 & 23 & 76.6 & 13 & 43.3 \\
\hline B7+8, B9+10 & -- & -- & 2 & 6.7 \\
\hline B7,B8, B9+10 & -- & -- & 4 & 13.3 \\
\hline B7+8, B9,B10 & -- & -- & 11 & 36.7 \\
\hline B7, B8+9+10 & 2 & 6.7 & -- & -- \\
\hline
\end{tabular}

Fig. 1: The right lung shows the absence of $B 7$.
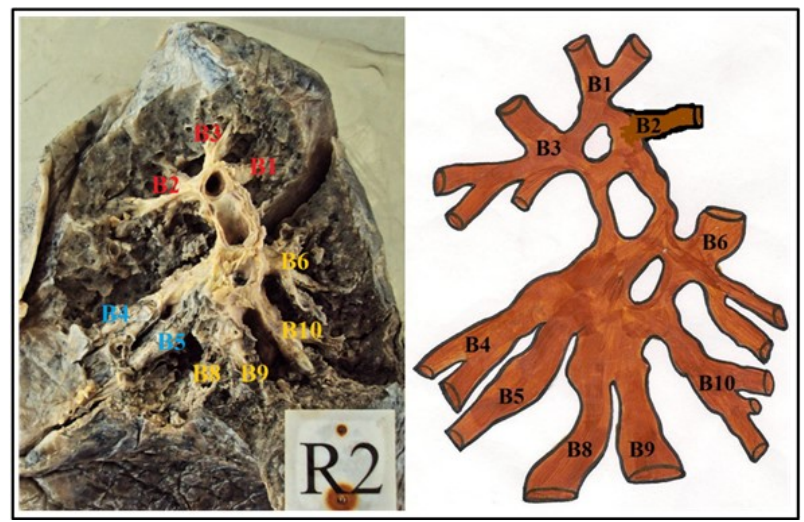
Fig. 2: The right lung shows the $B 7, B 8+9+10$.
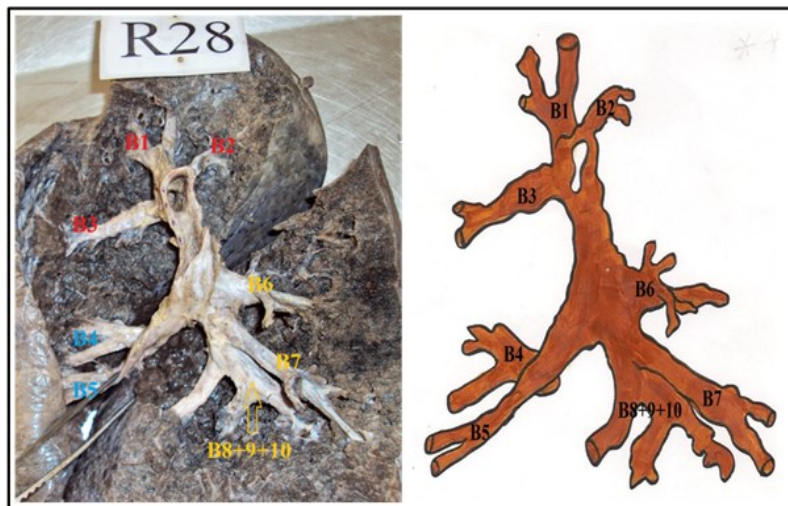

The incidence of variability in pattern of B1 to B10 was found to be more in left side. In left upper lobe (LUL), the variability of segmental pattern B1+B2, B3 and lingular segmental pattern i.e. B4 and B5 were observed in 2 lungs $(6.7 \%)$ and in 5 lungs (16.7\%) respectively. Out of the 5 lingular segmental patterns, two left lungs (6.7\%) exhibited an accessory bronchus after lingular division (Figure 4) and three left lungs (10\%) had three bronchi in lingular common trunk (Figure 5).

In case of left lower lobe (LLL), variability in segmental pattern was 17 lungs which accounts for $56.7 \%$. The patterns like i) $B 7+8, B 9+10$, ii) $\mathrm{B} 7, \mathrm{~B} 8, \mathrm{~B} 9+10$ and $\mathrm{iii}) \mathrm{B} 7+8, \mathrm{~B} 9, \mathrm{~B} 10$ was observed in $2(6.7 \%), 4(13.3 \%)$ and $11(36.7 \%)$ lungs respectively (Figure 3 ).

Fig. 3: Shows the variation of branching pattern in left lungs. A) B1+2, B3 pattern B) B7+8, B9+10 pattern C) B7, B8, $B 9+10$ pattern D) B7+8, B9, B10 pattern. A1, B1, C1 \& D1 shows the schematic representation.
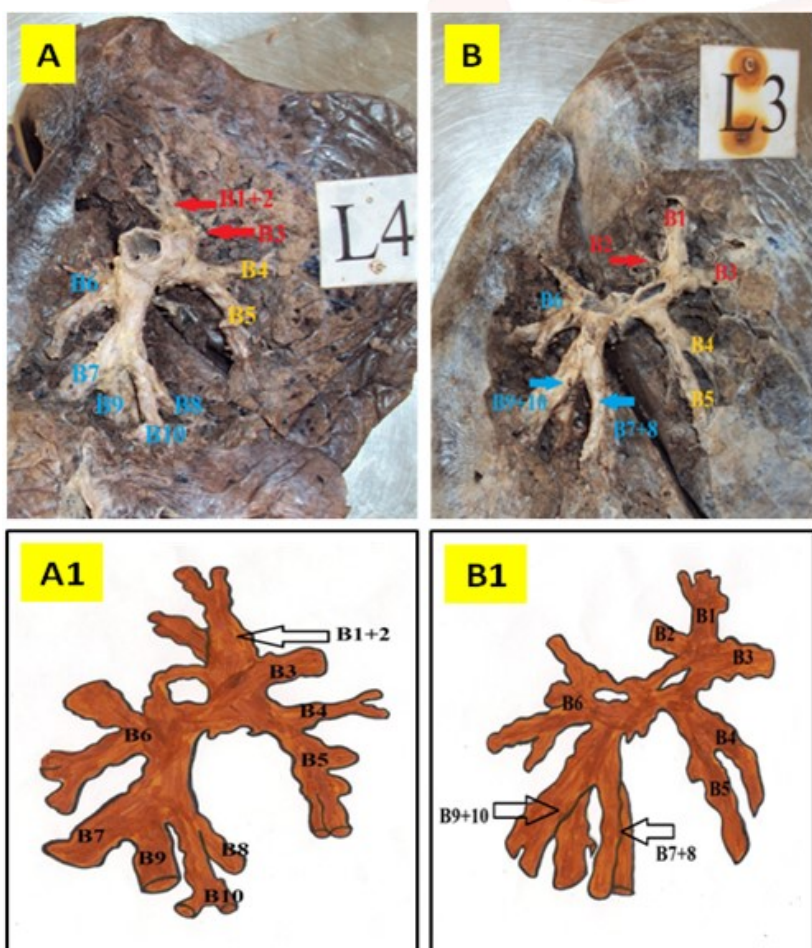

Fig. 4: shows extra bronchus after common lingular trunk $(X)$.

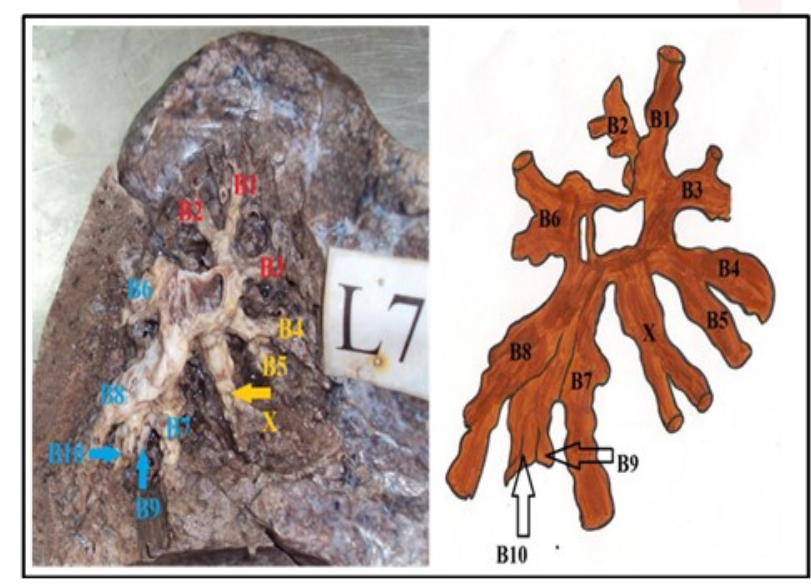

Int J Anat Res 2019, 7(3.3):6901-05. ISSN 2321-4287
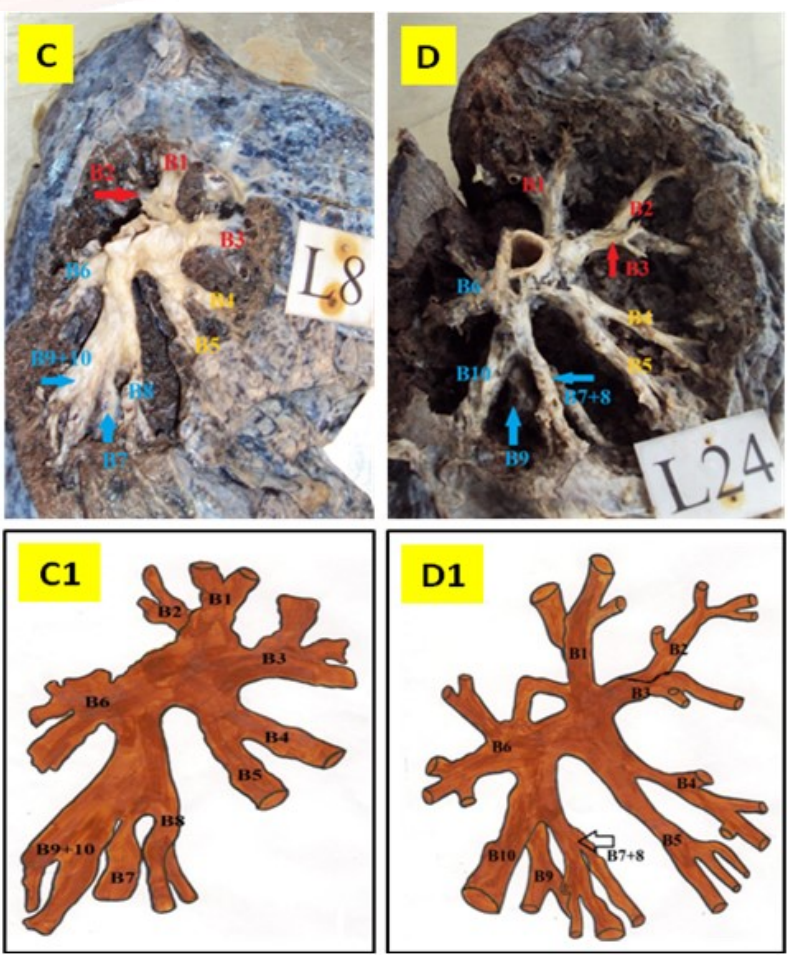

Fig. 5: Shows the three bronchi in lingular trunk (X).

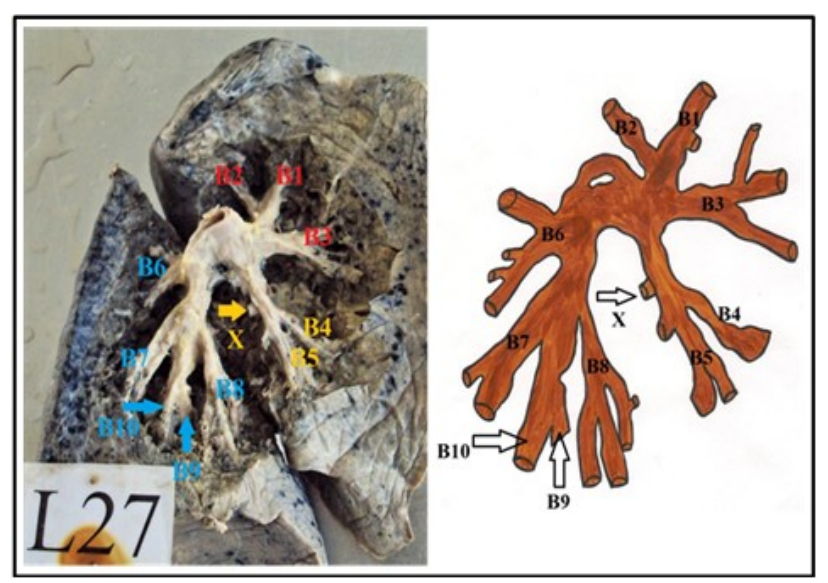




\section{DISCUSSION}

Table 3: Shows the incidence of variation in branching pattern of right middle, right and left upper lobes in different authors.

\begin{tabular}{|c|c|c|c|c|c|c|}
\hline \multirow{2}{*}{ Authors } & \multicolumn{3}{|c|}{ Right Lung } & \multicolumn{3}{c|}{ Left Lung } \\
\cline { 2 - 8 } & B1,B2,B3 & $\begin{array}{c}\text { B1,B2,B3, } \\
\text { X }\end{array}$ & $\begin{array}{c}\text { B4 and B5 } \\
\text { Medial , } \\
\text { Lateral }\end{array}$ & B1,B2,B3 & B1+2,B3 & $\begin{array}{c}\text { B4 Buperior, } \\
\text { Inferior Lingular }\end{array}$ \\
\hline Boyden \& Scannell (1948) [8] & $46 \%$ & $14 \%$ & $100 \%$ & - & - & - \\
\hline Ghaye (2001) [10] & $30 \%$ & - & $23 \%$ & $83 \%$ & $17 \%$ & $100 \%$ \\
\hline Cenk Kilic (2010) [9] & $86.70 \%$ & $13.33 \%$ & $6.70 \%$ & $40 \%$ & $60 \%$ & $60 \%$ \\
\hline Present Study (2019) & $100 \%$ & - & $100 \%$ & $93.30 \%$ & $6.70 \%$ & $83.30 \%$ \\
\hline
\end{tabular}

Several studies in the review of literature have Kilic et al and Ghaye et al which accounts for documented the morphology of lungs especially lobes and fissures. Many authors reported the normal as well as abnormal branching pattern of primary bronchi [2-6]. Very few studies using radiological or luminal casting methods have reported and focused on variability of branching pattern of segmental bronchi [7-9]. This is therefore the first proper conventional dissection methods without any dye or cast injection.

Right Middle, Right and Left Upper Lobes: Our data on right upper and middle lobe, the branching pattern of segmental bronchi slightly differed from previous data. In the present study, the normal pattern of B1, B2, B3 and B4, B5 was found to be in $100 \%$. But on the contrary, Boyden et al and Cenk Kilic et al had reported the abnormal branching pattern in right upper lobe with the incidence of $14 \%$ and $13.33 \%$ respectively $[8,9]$. The lowest incidence of normal pattern of B1, B2, B3 in the right upper lobe was documented by Ghaye et al which accounts for $30 \%{ }^{10}$ and similarly, the lowest incidence of normal pattern of B4, B5 in right middle lobe was observed by Cenk Kilic et al which accounts for $6.7 \%$ [9].

In the present study, the incidence of normal pattern of B1, B2, B3 was found to be the highest (93.3) in left upper lobe followed by Cenk $40 \%$ and $83 \%$ respectively $[9,10]$. We also found the incidence of an accessory bronchus in relation to common lingular trunk. An accessory bronchus may arise either separately as extra bronchus or as additional branch in the common lingular trunk. We acknowledged an extra bronchus in two lungs (6.7\%) which exhibited as an accessory bronchus after lingular division andfound the common lingular trunk exhibiting three divisions in three lungs (10\%). Comparison of incidence of accessory bronchi in relation to common lingular trunk with Cenk Kilic was described in table 4.

Table 4: Shows the incidence of accessory bronchi in relation to common lingular trunk in different authors.

\begin{tabular}{|c|c|c|}
\hline \multirow{2}{*}{ Authors } & \multicolumn{2}{|c|}{ B4 and B5 lingular bronchi } \\
\cline { 2 - 3 } & An extra bronchus & Three bronchi \\
\hline Cenk Kilic (2010) [9] & $13.33 \%$ & $46.70 \%$ \\
\hline Present Study (2019) & $6.70 \%$ & $10 \%$ \\
\hline
\end{tabular}

Right and Left Lower Lobes: Pattern variability was more in lower lobes than upper and middle lobes. Authors like Smith et al [11] and Ferry et al [12] conducted their study only on right lower lobe and Berg et al [13] conducted on left lower lobe only, whereas Cenk kilik et al [9], Ghaye et al [10], and Naidich et al [14] conducted studies on both right and left lower lobe (table 5).

Table 5: The incidence of variation in branching pattern of left and right lower lobes in different authors.

\begin{tabular}{|c|c|c|c|c|c|c|c|c|c|c|c|c|}
\hline \multirow{2}{*}{ Authors } & \multicolumn{2}{|c|}{ B7 absent } & \multicolumn{2}{|c|}{$B 7, B 8, B 9, B 10$} & \multicolumn{2}{|c|}{$B 7+8, B 9+10$} & \multicolumn{2}{|c|}{$B 7, B 8, B 9+10$} & \multicolumn{2}{|c|}{$\mathrm{B} 7+8, \mathrm{~B} 9, \mathrm{~B} 10$} & \multicolumn{2}{|c|}{$B 7, B 8+9+10$} \\
\hline & $R$ & $\mathrm{~L}$ & $R$ & L & $R$ & $\mathrm{~L}$ & $R$ & $L$ & $R$ & $\mathrm{~L}$ & $R$ & $\mathrm{~L}$ \\
\hline Berg (1949) [13] & - & $3 \%$ & - & $0 \%$ & - & $67 \%$ & - & $0 \%$ & - & $13 \%$ & - & - \\
\hline Smith \& Boyden (1949) [11] & $14 \%$ & - & - & - & - & - & - & - & - & - & - & - \\
\hline Ferry \& Boyden (1951) [12] & $20 \%$ & - & - & - & - & - & - & - & - & - & - & - \\
\hline Naidich (1999) [14] & - & $<5 \%$ & $15 \%$ & $35 \%$ & - & $45 \%$ & $60 \%$ & - & - & $15 \%$ & - & - \\
\hline Ghaye (2001) [10] & $10 \%$ & - & $6 \%$ & $0 \%$ & $3 \%$ & $76 \%$ & $68 \%$ & & & $10 \%$ & $10 \%$ & - \\
\hline Cenk Kilic (2010) [9] & $13.33 \%$ & $6.70 \%$ & $20 \%$ & $0 \%$ & $6.70 \%$ & $53.33 \%$ & $53.33 \%$ & - & & $26.66 \%$ & $6.70 \%$ & - \\
\hline Present Study (2019) & $16.70 \%$ & $0 \%$ & $76.60 \%$ & $43.30 \%$ & $0 \%$ & $6.70 \%$ & $0 \%$ & $13.30 \%$ & $0 \%$ & $36.70 \%$ & $6.70 \%$ & $0 \%$ \\
\hline
\end{tabular}


Limitation of study is that our study was confined only to the variability to branching pattern of segmental bronchi B1 to B10. The present study can be correlated with other methods like luminal casting and tracheobronchial imaging. The knowledge of anatomical variability of branching pattern is important for the radiologist and surgeons for planning segmental resections or pulmonary lobectomy.

\section{CONCLUSION}

In the present study, irregular pattern was found to be more on left side. The patterns like $\mathrm{B} 1+\mathrm{B} 2, \mathrm{~B} 3(6.7 \%), \mathrm{B} 7+8, \mathrm{~B} 9+10(6.7 \%), \mathrm{B} 7, \mathrm{~B} 8$, $B 9+10(13.3 \%)$ and $B 7+8, B 9, B 10(36.7 \%)$ was seen only in the left lungs, whereas the pattern B7, B8+9+10(6.7\%), was seen only on right side. The incidence of absence of B7 pattern was found only on right side (16.7\%). We acknowledge and conclude form previous as well as present study, that branching pattern of tracheobronchial tree is not constant and knowledge of variability is useful for interventional radiologist and cardiothoracic surgeons. With the advancement of imaging technology, it is now possible to study the normal tracheobronchial anatomy and its variant, which helps to diagnose or predict many adverse outcomes of chest diseases at earlier stage.

\section{Conflicts of Interests: None}

\section{REFERENCES}

[1]. Shah P, Johnson D, standring S. Thorax. In: Gray's Anatomy. 39th ed. Edinburgh: Churchill Livingstone; 2005.p. 1068-9.

[2]. Gonlugur U, Efeoglu T, Kaptanoglu M, Akkurt I.Major anatomical variations of the tracheobronchial tree: Bronchoscopic observation. Anat Sci Int. 2005; 80:111-5.
[3]. Vassiou K, Kotrogianni F, Lavdas E, Vlychou M, Fanariotis M, Arvanitis DL, et al. Tracheobronchial variations evaluated by multidetector computed tomography and virtual bronchoscopy. OA Case Reports 2013 Mar 01;2 (3):23.

[4]. Vaz Rodrigues L. Anatomia endobrônquica: Rev Port Pneumol. 2011; 17(5):211-215.

[5]. A. Savkovi et al.: Ventilatory Patterns of Left Upper Lobe, Coll. Antropol. 28 (2004) 2: 701-709.

[6]. Vishnu Sharma et al, Major Anatomical Variations in the Division of Tracheobronchial Tree as Visualised by Fiberoptic Bronchoscopy, Capsula Eburnea 2011, 6(7):33-36.

[7]. Boyden EA, Hamre CJ. An analysis of variations in the bronchovascular patterns of the middle lobe in fifty dissected and twenty injected lungs. J Thorac Surg. 1951;21:172-88.

[8]. Boyden EA, Scannell JG. An analysis of variations in the bronchovascular pattern of the right upper lobe of fifty lungs. Am J Anat. 1948; 82:27-72.

[9]. Kýlýç C, Kirici Y, Ozan H, Ađacý B. Variations in Patterns of Bronchial Tree, J.Clin.Anal.Med. 2010;1(3):34-38.1

[10]. Ghaye B, Szapiro D, Fanchams JM, Dondelinger RF. Congenital bronchial abnormalities revisited. Radiographics. 2001;21:105-19.

[11]. Smith FR, Boyden EA. An analysis of variations of the segmental bronchi of the right lower lobe of fifty injected lungs. J Thorac Surg. 1949;18:195215.

[12].Ferry RM, Boyden EA. Variations in the bronchovascular patterns of the right lower lobe of fifty lungs. J Thorac Surg. 1951;22:188- 201.

[13]. Berg RM, Boyden EA, Smith FR. An analysis of variations of segmental bronchi of the left lower lobe of fifty dissected, and ten injected lungs. J Thorac Surg. 1949;18:216-37.

[14]. Naidich DP, Webb WR, Müller NL, Krinsky GA, Zerhovni EA, Siegelma SS, editors. Computed tomography and magnetic resonance of the thorax. 3th ed. Philadelphia: Lippincott Williams \& Wilkins; 1999. p. $169-226$.

How to cite this article:

Umesh. S.N, Khizer Hussain Afroze. M, Sangeeta. M. VARIATIONS

IN BRANCHING PATTERN OF SEGMENTAL BRONCHI IN LUNGS

USING CONVENTIONAL DISSECTION METHOD. Int J Anat Res 2019;7(3.3):6901-6905. DOI: 10.16965/ijar.2019.252 